\title{
The Federal Budget: From Surplus to Deficit
}

T HE MAGNITUDE of the Federal budget deficit has been in the spotlight in recent discussions of economic trends and prospects. Analyses of the Fed. eral budget indicate the likelihood of continuing deficits for the next several years, given the current structure of tax rates and existing Government spending programs. ${ }^{1}$ Just a few years ago the concept of "fiscal drag" was used to describe the tendency of the budget toward chronic surplus. ${ }^{2}$ Why has there been a shift in the assessment of the outlook for the Federal budget?

The purpose of this note is to give a brief quantitative summary of the factors which have contributed to the change in the budget position since early 1969. These factors are divided into two primary effects: (1) a discretionary effect relating to changes in tax rates and expenditure programs, and (2) an economic activity effect relating to the effect of the degree of resource utilization on the size of the tax base and the amount of unemployment benefits. The first half of 1969 is chosen as a base for comparison because this period represents both a high-employment level of economic activity and the most recent peak in the time series of the net Federal budget position (the excess of receipts over expenditures), ${ }^{3}$ Since early 1969, some tax rates have been reduced, expenditures have continued to increase, and the rate of resource utilization has remained below the level attained in that period. What is the contribution of each of these factors to the deficit as it currently exists, and, given this background, what is the outlook for the Federal budget?

\section{Factors Contribnting to the Current Federal Budget Defort}

The Federal budget (national income accounts basis) moved from a $\$ 10$ billion annual rate of surplus in the first half of calendar 1969 to an $\$ 18$ billion rate

\footnotetext{
1Recent analyses of the Federal budget are found in Charles L. Schultze et al., Setting National Priorities, The 1973 Budget (Washington, D.C.; The Brookings Institution, 1972) and David J. Ott et al., Nixon, McGovern and the Federal Budget, Domestic Affairs Study 8, American Enterprise Institute for Public Policy Research, Washington, D.C. (September 1972)

${ }^{2}$ For a review of recent fiscal history, see Schultze et al., Setting National Priorities, chap. 12.

3Throughout this article all time references are to calendar years, and all budget references are on a national income accounts basis.
}

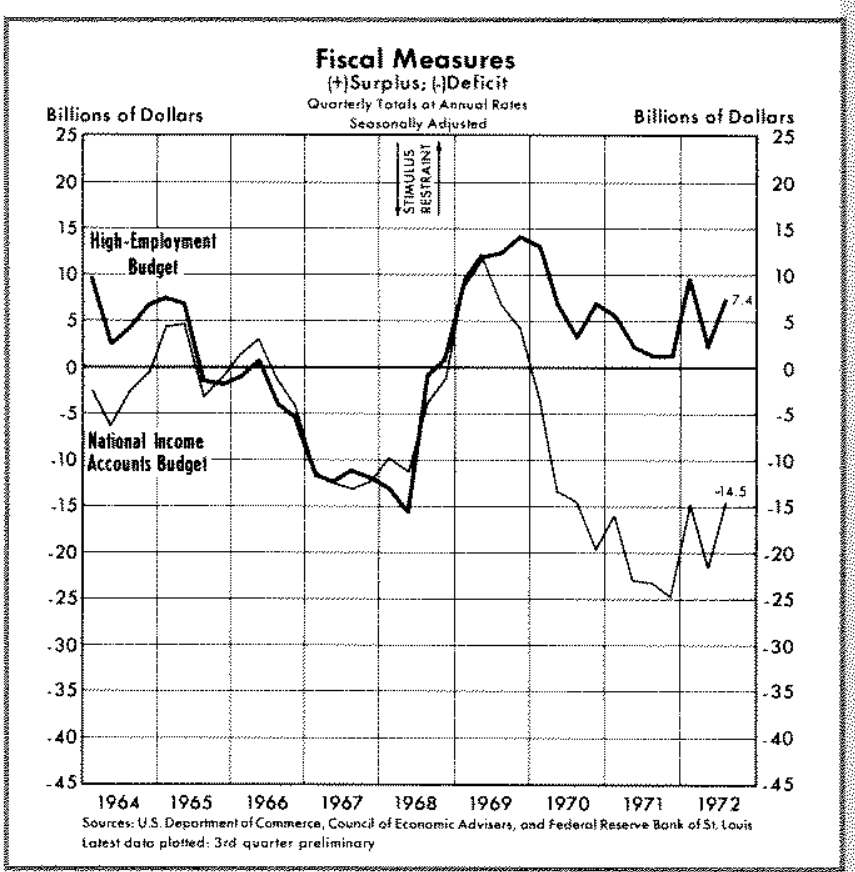

of deficit in the first half of 1972. The following tables provide estimates of the contributions of various factors to this shift from surplus to deficit.

Table I gives the Federal budget for the first half of 1972 if the economy had continued to operate at high-employment levels and the expenditure and revenue relationships of the first half of 1969 had been maintained. In other words, given the schedule of tax

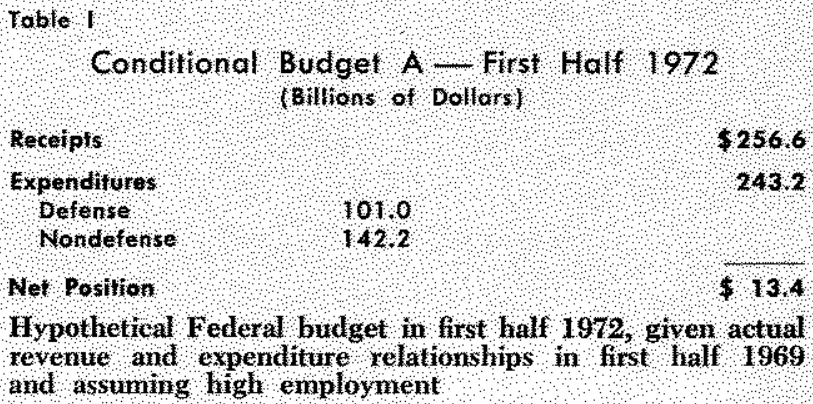
Nondetense

Net position

$\$ 256.6$ 243.2

$\$ 13,4$

Hypothetical Federal budget in first half 1972 , given actual revenue and expenditure relationships in first half 1969 and assuming high enployment

rates in early 1969, the magnitude of Government expenditures relative to the size of the economy (measured by potential GNP in current dollars) at that time, and the maintenance of a high-employment level of activity, extrapolation of these relationships into early 1972 would have yielded the budget situa. tion as summarized in Table I. A $\$ 13.4$ billion rate of surplus would have prevailed, given these hypothetical conditions. 
Table II shows the Federal budget at an assumed high-employment level of economic activity, but is calculated by using the revenue and expenditure relationships that prevailed in early 1972. The differences between Tables I and II then, reflect changes in tax rates and expenditure changes relative to the size of the economy. Under these high-employment conditions the budget would have shown a $\$ 6$ billion rate of surplus.

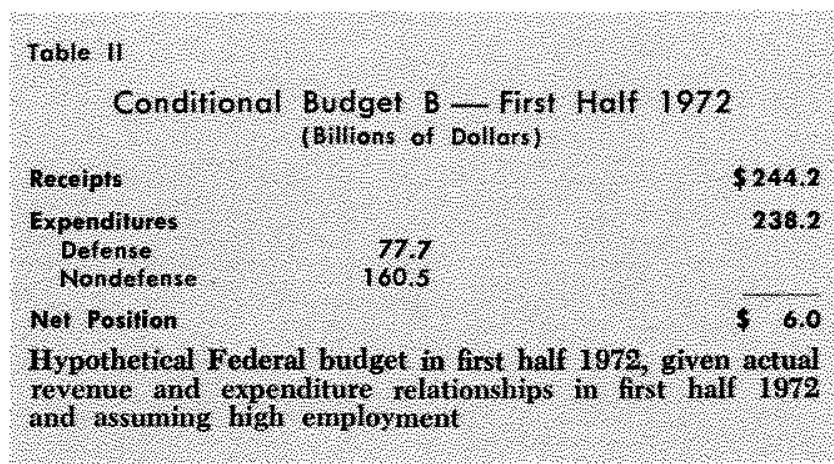

Table III gives the actual budget for the first half of 1972. The differences between Tables II and III represent the effects of a change in the relative rate of resource utilization on the budget. Expenditures and revenues deviated from their hypothetical highemployment values because the economy was operating below that hypothetical level of activity. The budget was in deficit at an annual rate of more than $\$ 18$ billion.

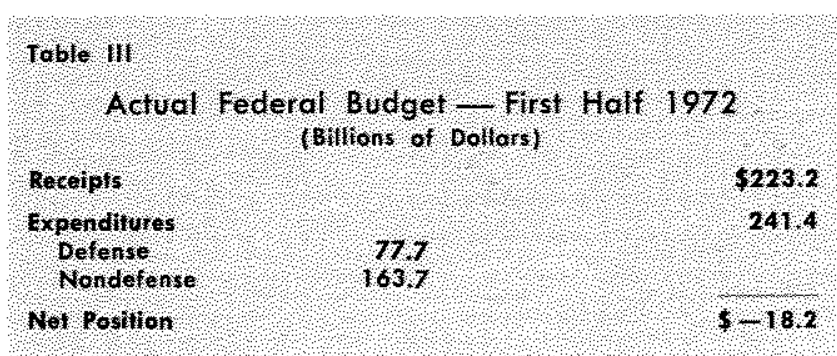

The information in Tables I-III is combined in Table IV to summarize the factors which contributed to the shift from a substantial surplus to a substantial deficit. Table IV is interpreted as follows. The surplus was $\$ 31.6$ billion less in the first half of 1972 than it would have been if the revenue-expenditure relationships of first half 1969 had been maintained along with high employment. The slowdown of economic activity contributed $\$ 24.2$ billion $(\$ 21+\$ 3.2)$ to the $\$ 31.6$ billion decline in the surplus (the shift to deficit). The remaining $\$ 7.4$ billion $(\$ 12.4-\$ 5.0)$ is attributable to the effect of discretionary fiscal actions. Tax rate changes - reflecting removal of the tax surcharge, the Tax Reform Act of 1969, and the Revenue Act of 1971
- contributed $\$ 20.4$ billion toward the decline in the surplus, while overwithholding of personal income taxes acted to increase the surplus (reduce the deficit) at an annual rate of $\$ 8$ billion. Discretionary expenditures contributed toward an increase in the surplus by $\$ 5$ billion $(\$ 23.3-\$ 18.3)$. This tendency can be attributed solely to the slowdown of defense spending which more than offset the tendency-towarddeficit effects of nondefense expenditure increases.

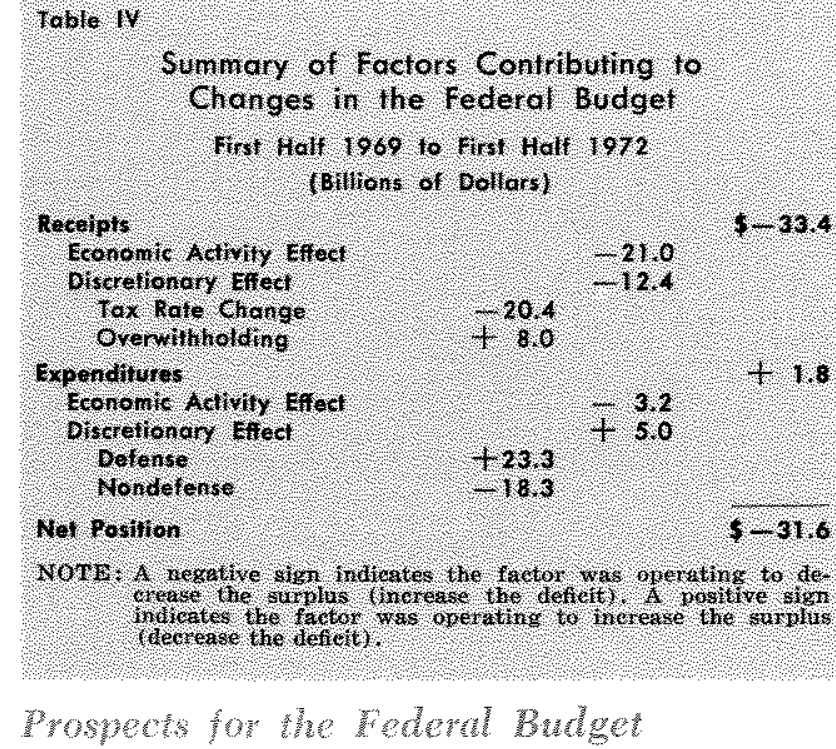

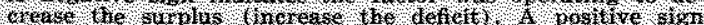
indicates the facter was operating to therease the surwits (Tlerease the defiet).

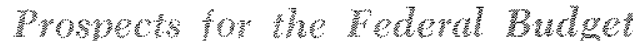

Given this background of recent budget experience, what are the prospects for the future? Table $\mathrm{V}$ gives estimates for 1975 as prepared by the American Enterprise Institute. ${ }^{4}$ These figures are based on the assumption that high employment will prevail in 1975 and that prices will be increasing at a 2.5 percent annual rate. The revenue estimate is based on the prospects for tax rates as of late August 1972 . Expenditure estimates represent a projection of existing Government programs along with allowance for pending legislation as of August 1972. Thus the \$21.5 billion deficit represents only a projection of the budget situation at that time and does not allow for possible expansion of Government spending programs.

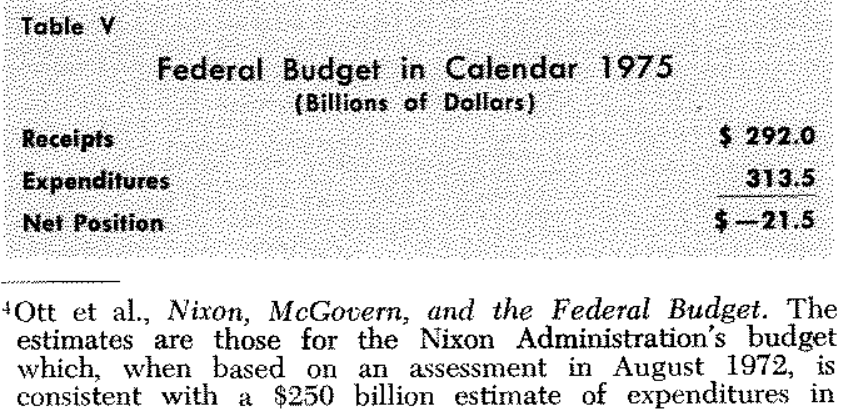

${ }^{4}$ Ott et al., Nixon, McGovern, and the Federal Budget. The estimates are those for the Nixon Administration's budget which, when based on an assessment in August 1972, is consistent with a $\$ 250$ billion estimate of expenditures in 


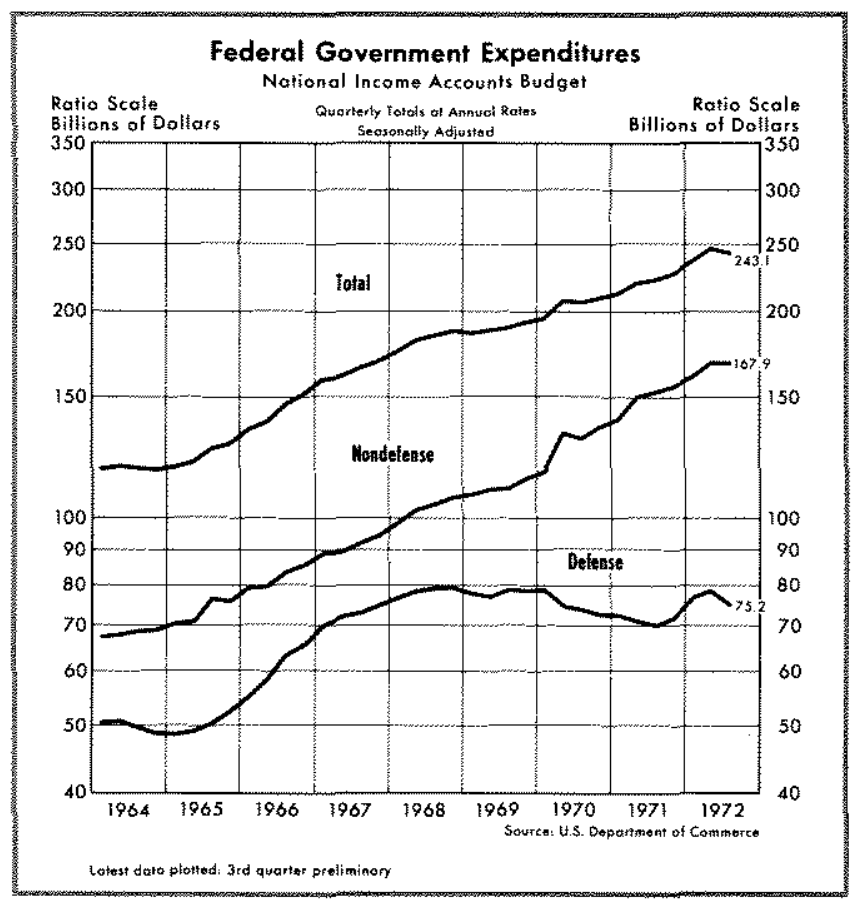

Prospects for the future focus on the expenditure side of the budget. They indicate a substantial budget deficit, even under conditions of high employment, as compared to the hypothetical surplus shown in Table II. Gains in the budget position from reduced defense spending, like those shown in Table IV, do not appear to be in prospect for the future. The existing tax structure would not be sufficient, given existing expenditure programs, to bring the budget into balance, even if the economy returns to high employment.

\section{Shblization Molicalons}

What conclusions can be drawn? First, the current budget deficit is attributable in large measure to a slowdown in economic activity, but tax changes and a rapid growth of nondefense expenditures have also contributed to the situation. Defense expenditure trends have actually worked to reduce the deficit, mainly due to reductions in Vietnam expenditures.

fiscal 1973. Calendar 1975 is chosen for illustrative purposes because it is far enough into the future to allow a focus on fundamental budget trends while providing sufficient time to actually achieve the assuned high-employment level of activity. The American Enterprise Institute study presents projections through 1980.
Future budget prospects raise questions about the options available to policymakers in dealing with the problem of expenditure growth in excess of receipts. First, there is the option of reducing existing expenditure programs. Second, there is the consideration of growth in new programs which yield an even larger deficit than that shown in Table $V$, other things equal. Third, there is the option of raising tax rates. Changes in the effective rate for social security taxes are scheduled, but these are not large enough to erase the deficit by 1975 . Once the decision about expenditures and taxes has been made, any deficit that remains is financed by the sale of Government bonds to the private sector of the economy, at least initially. However, the ultimate effects of the deficit depend on how much of the Government debt is subsequently monetized by the Federal Reserve System. ${ }^{5}$

The alternative of raising tax rates to increase revenues has to be weighed against any tendency of such an action to perpetuate existing Government programs, whether or not they are justified on a costbenefit basis. Furthermore, there is the question of whether new programs are scrutinized as carefully when revenues are "available" to be spent.

The alternative of financing the excess of Government expenditures over receipts by debt sales to the private sector means, other things equal, a rise in interest rates in the short run. Monetization of such debt by the Federal Reserve System, on the other hand, reduces interest rates in the short run from what they would otherwise be, but over a longer horizon can lead to more price inflation and, ultimately, higher interest rates. Curtailing growth of new Government programs and cutting back existing programs would be a step in the direction of avoiding higher tax rates, higher interest rates, and more rapid inflation. Such a course of action, however, has to be assessed against the foregone benefits of the programs themselves.

5All of the options ignore the feedback of these budget. alternatives on the course of the economy. Thus implicitly there is the assumption that monetary actions can be implemented in such a way as to achieve high employment by 1975 , given the particular budget alternative which is followed. Comparing the consequences of the budget alternatives probably implies different courses of monetary action.

More detailed study of the impact of these various alterna-

tives would probably recuire the use of an econometric model.

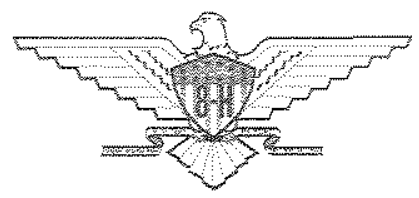

